\title{
Non-linear FEM Analysis of seismic induced pounding between neighbouring Multi-storey Structures \\ Mohammed Jameel ${ }^{a}$, \\ A.B.M. Saiful Islam ${ }^{a}$, \\ Raja Rizwan Hussain*, b, Syed Danish Hasanc, M. Khaleel ${ }^{\mathrm{a}}$ \\ ${ }^{a}$ Department of Civil Engineering, University of Malaya, 50603 Kuala Lumpur, Malaysia \\ ${ }^{b}$ Asst. Professor, CoE-CRT, Department of Civil Engineering, College of Engineering, King Saud University, Riyadh, Saudi Arabia \\ ' Civil Engineering Section, Aligarh Muslim University, Aligarh-202002, India \\ Received 05 May 2012 \\ In revised form 04 Feb 2013 \\ *Author email: raja386@hotmail.com
}

\begin{abstract}
Pounding of neighbouring construction of structures due to seismic excitation increases the damage of structural components or even causes collapse of structures. Among the possible building damages, earthquake induced pounding has been commonly observed in several earthquakes. Therefore it is imperative to consider pounding effect for structures. This study aims to understand the response behaviour of adjacent buildings with dissimilar heights under earthquake induced pounding. Effects of different separation distances between structures are also investigated. Nonlinear finite element analysis in time domain has been carried out for pounding of neighbouring structures having varying heights. To show the importance of avoiding pounding in structures the results obtained were compared with model having no pounding phenomena. The results were obtained in the form of storey shear, pounding force, storey drift, point displacement and acceleration. The acceleration at pounding level significantly increases during collision of building. The generated extra pounding force may cause severe damage to structural members of structures. Pounding produces shear at various story levels, which are greater than those obtained from no pounding case. Building with more height suffers greater damage than shorter building when pounding occurs. Increasing gap distance tends to reduce story shear in consistent manner. The results also show that the conventional modelling of building considering only beams and columns underestimates pounding effects. More realistic modelling such as beams, columns and slabs shall be adopted to accurately understand the pounding phenomenon.
\end{abstract}

\section{Keywords}

Structural pounding effect; Neighbouring Structures; Pounding level; gap element; Separation distance; Seismic induced blow.

\section{INTRODUCTION}

Under earthquakes excitation, structures will be displaced and deformed. When two structures are close together, it is expected that they will pound against each other. There are many structures 
which are built close to each other and could experience seismic pounding in future earthquakes. This situation can be easily seen in highly populated cities. Pounding of adjacent structures increases the damage of structural components. It may even cause collapse of structures. The earthquake that struck Mexico City in 1985 has revealed the fact that pounding was present in more than $40 \%$ of 330 collapsed or severely damaged structures [1]. Furthermore, even in those cases where it does not result in significant structural damage, pounding always induces higher floor acceleration in the form of large magnitude short duration pulses, which in turn cause greater damage to building contents $[2-5]$.

Pounding effect for varying separation distance has been covered by several researchers with equal floor heights [6,7]. It is shown that constructing adjacent structures with equal floor heights and separation distances reduces the effects of pounding considerably. Study on seismic separation device has also been performed by several researchers [8-11]. Kasai and Maison [12] investigated the building pounding damage during the 1989 Loma Prieta earthquake. Jankowski [13] presented nonlinear viscoelastic modelling of earthquake-induced structural pounding. Jankowski [14] reported that the increase in structural damping of adjacent structures simultaneously leads to the extension of the region in the spectrum where the impact force is equal to zero.

The height ratio of two structures significantly changes the storey shear of structures which was shown by Jeng and Tzeng [15]. Numerical analysis has been conducted by Jankowski [14] for different mass ratio of structures. The pounding force response spectra for the El Centro earthquake confirm that the increase in mass value leads to considerable increase in peak impact force. Jankowski [16] performed non-linear analysis for earthquake-induced pounding of two equal height structures with substantially different dynamic properties. This response analysis show that collisions have a significant influence on the behaviour of the lighter and more flexible building especially in longitudinal direction causing generous amplification of the response and lead to extensive permanent deformation due to yielding [17-20]. Associated with the possibility of seismic vulnerability, automated mitigation of responses is required to be assessed [21-26] in construction technology.

Seismic codes and regulations state the minimum separation distances to be provided between adjacent structures which are equal to the relative displacement of two potentially colliding structures. For instance International Building Code [27], Clause 1613.6.7, stated all structures and structures shall be separated from adjoining structures. However, providing large separation distance between structures is not a good solution due to several factors. Firstly, the building code is inconsistent with the actual condition during earthquakes where large inelastic deformations can occur and structures may not be secured. Secondly, the land in high density cities is a valuable asset financially. Thirdly, structural pounding involves structures nearby which may not be developed at the same time or by same party. Therefore, it is necessary to measure pounding effect in building to develop better damage control and more efficient use of land space.

The study on pounding between two dissimilar height neighbouring structures under seismic loading has been rarely done. Therefore, pounding response of 3D frame structures with multiple degree of freedom (MDOF) systems is also hardly investigated. So the objective of the study is to evaluate 
- the structural response behaviour of structures in seismic-induced pounding in a 3D frame system with 6 degrees of freedom resembling to practical structures

- The alteration of structural behaviours for dissimilar heights of adjacent structures

- the effects of different separation distances in between structures are studied in addition

- the parameters in forms of displacement, acceleration, storey drift, pounding force and storey shear

- the influence of structural mass of adjacent structures on the seismic pounding forces

- the difference of results between different modelling techniques, "frame + slab" model with the only "frame" model

- justify more realistic modelling such as beams, columns and slabs adopted to accurately understand the pounding phenomenon.

\section{METHODOLOGY}

This study is carried out by analysing reinforced concrete frames using nonlinear time history analysis. Seismic and pounding responses of two multi-storey structures are studied in aspects of displacement, storey drift, pounding force and storey shear. Type of pounding being analysed is the pounding effect where shorter building collides to adjacent taller building. Besides, frame and slab model is modelled to understand the influence of modelling

\subsection{Gap Elements in Building Construction}

Gap has been defined as link elements in ETABS [28]. It is a compression-only element required to assess the force of pounding and simulate the effect of pounding. The purpose of the gap element is to transmit the force through link only when contact occurs and the gap is closed. The nonlinear force-deformation relationship is given by Eqn. (1).

$$
f=\left\{\begin{array}{cc}
K(d-\text { open }) & \text { if } d-\text { open }<0 \\
0 & \text { otherwise }
\end{array}\right.
$$

Where $\mathrm{K}$ is the spring constant, $\mathrm{d}$ denotes the displacement, and open is the initial gap opening, which must be zero or positive.

Stiffness, $\mathrm{K}$ for gap elements is recommended one or two orders of magnitude greater than the horizontal equivalent springs representing both structures at fourth storey level. The way of selecting stiffness for the gap elements is chosen as 100 times greater value than the relation $\mathrm{AE} / \mathrm{L}$. It this worth mentioning that $\mathrm{A}$ is the cross-sectional area of the element, $\mathrm{E}$ is the modulus of elasticity, and $\mathrm{L}$ is the length of the element in the direction perpendicular to the contact surfaces. Therefore, in this model $\mathrm{K}$ is calculated as follows.

$$
\begin{gathered}
K=\frac{E A}{L} \times 100 \\
K=\frac{\text { Modulus of elasticity } \text { of concrete } \times \text { area } \text { of contact surface }}{\text { length } \text { of element } \text { of contact surface }} \times 100
\end{gathered}
$$


Energy dissipation during contact can be accounted by damping. Gap element should include the effect of linear effective stiffness and damping to achieve desired contact behaviour.

\subsection{Nonlinear Dynamic Analysis of Building Construction}

Nonlinear dynamic analysis has been carried out considering familiar earthquake seismic record El Centro. Finite element analysis package ETABS is found to be more appropriate for the current study. The governing equations of motion are obtained considering equilibrium of all forces at each degree of freedom. The equations of motion for the structure are written in Eq. (4).

$$
[M]\left\{\ddot{y}_{b}\right\}+[C]\{\dot{y}\}+[K]\{y\}=-[M]\left[T_{g}\right]\left\{\ddot{y}_{g}\right\}
$$

Where, $[\mathrm{M}],[\mathrm{K}]$ and $[\mathrm{C}]$ are the mass, damping and stiffness matrices of the superstructure respectively; $\{\mathrm{y}\}$ and $\left\{\mathrm{y}_{\mathrm{b}}\right\}$, are displacement of super structure and base; $\left\{\ddot{\mathrm{y}}_{\mathrm{b}}\right\}$ and $\left\{\ddot{\mathrm{y}}_{\mathrm{g}}\right\}$ are base acceleration and acceleration relative to the ground; $\left[\mathrm{T}_{\mathrm{g}}\right]$ is the earthquake influence coefficient matrix.

All nonlinearities are restricted to the nonlinear link elements only. The above dynamic equilibrium equations considering the super structure as elastic and link as nonlinear can be written as:

$$
\left.[M]\{\ddot{y}(t)\}+[C]\{\dot{y}(t)\}+\left[K_{L}\right]\{y(t)\}+r_{N}(t)=r(t)-\left[r_{N}(t)-K_{N} y(t)\right]\right)
$$

where

$$
K=K_{L}+K_{N}
$$

$\mathrm{K}_{\mathrm{L}}=$ stiffness matrix of all linear elements; $\mathrm{K}_{\mathrm{N}}=$ stiffness matrix for all of the nonlinear degrees of freedom. $\mathrm{C}$ is the proportional damping matrix; $M$ is the diagonal mass matrix; $r_{N}$ is the vector of forces from nonlinear degrees of freedom in the gap elements; $y, \dot{y}$, and $\ddot{y}$ are the relative displacement, velocity and acceleration with respect to ground; $r$ is the vector of applied loads. The effective stiffness at nonlinear degrees of freedom is arbitrary, but varies between zero and the maximum stiffness of that degree of freedom.

\subsection{Solution Technique}

Fast nonlinear analysis (FNA) automated technique suggested by Wilson [29] has been considered for solution of equlibrium equations. The method is extremely efficient as it is designed for structural systems which are primarily linearelastic, but have limited number of predefined nonlinear elements. For FNA method, all nonlinearities are restricted to the gap elements. The specific time history load is applied quasi-statically with high damping. The FNA analysis considers a ramp type of time history function which increases linearly from zero to one over a length of time. The nonlinear equations are solved iteratively in each time step. The program considers that the analysis results vary during a time step. The iterations are carried out until the solution converges. If

Latin American Journal of Solids and Structures 10(2013) $921-939$ 
convergence can not be achieved, the program divides the time step into smaller substeps and tries again.

\section{NUMERICAL INVESTIGATION OF STRUCTURES}

In this research, two adjacent structures of different height are modelled. The structures are four storeys (16.16 $\mathrm{m}$ in height) and seven storeys (28 $\mathrm{m}$ in height). The structures are reinforced concrete frames which consist of square columns of dimension $500 \times 500 \mathrm{~mm}$, all beams of dimension $400 \times 250 \mathrm{~mm}$. 6 - ASTM \#7 bars are provided for every column's vertical grade-60 steel. In addition, $200 \mathrm{~mm}$ slab thickness has been chosen in frame-slab model case. Gap elements are linked at 4 nodes between the structures at the roof level of lower building in order to simulate contact between two surfaces by generating forces when the two surfaces approach each other. The plan and elevation of the structures are as in Figure 1 as below.
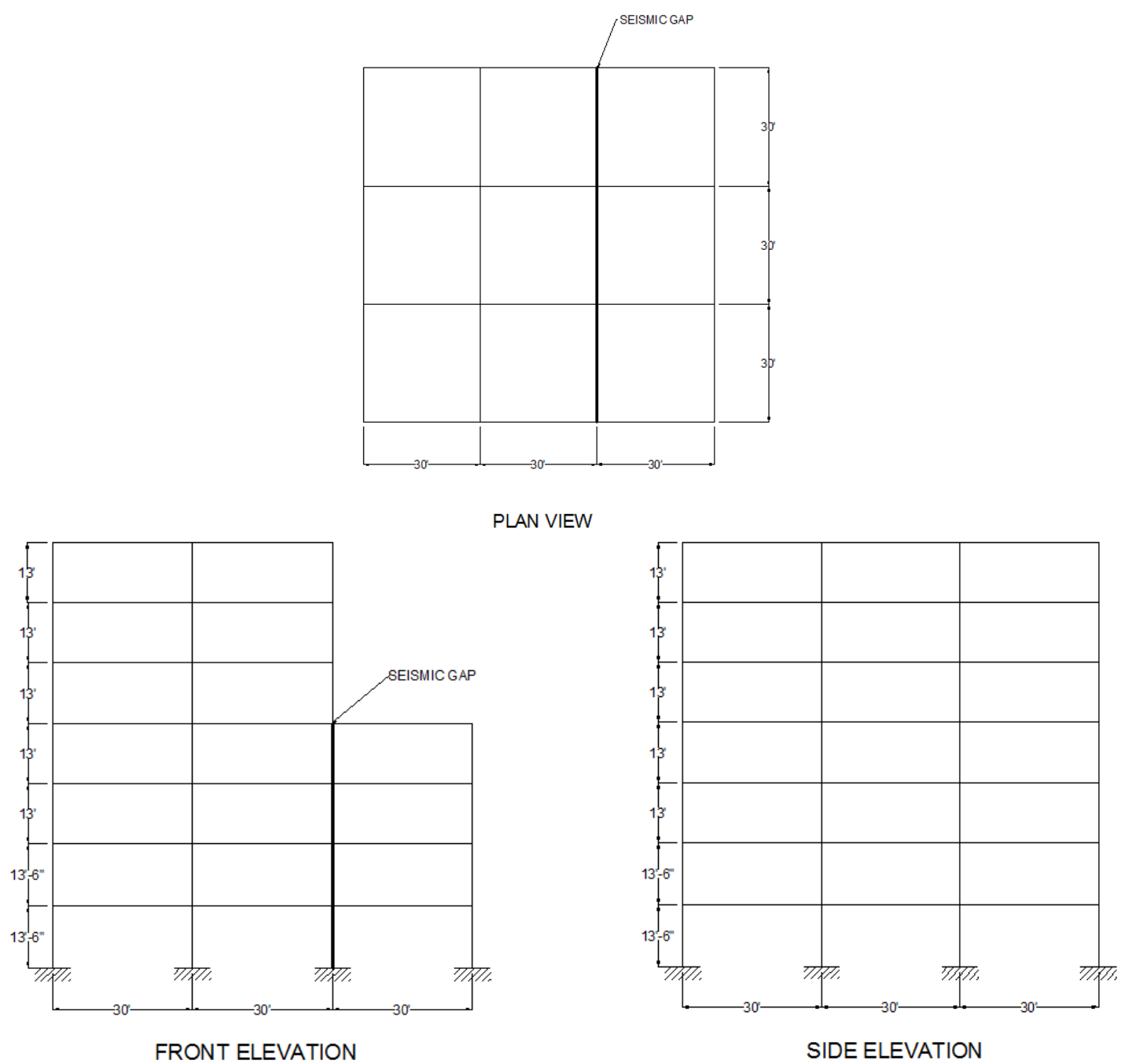

Figure 1 Plan view and elevations of the building construction 
Modulus of elasticity of concrete has been chosen as $25000 \mathrm{MPa}$. Gap is defined as link elements having stiffness $1100000 \mathrm{KN} / \mathrm{mm}$. Energy dissipation during contact is accounted by damping. Gap element includes the effect of linear effective stiffness and damping to achieve desired contact behaviour.

Seismic time history function is selected as the ground excitation data of El Centro earthquake (magnitude 7.1) in year 1940 is used. Total duration of this time history function is 12.113 seconds. It has a peak pounding acceleration of $0.319 \mathrm{~g}$ at time 2.006 seconds. It is applied for both longitudinal and traverse direction. The graph of the functions is illustrated in Figure 2.

\section{RESULTS AND DISCUSSIONS}

Most previous researches were often carried out in single degree of freedom system, plane frame and rarely utilize finite element software. In this study, pounding effect of a four and seven storey structures subjected to seismic load is analysed by using finite element code ETABS [28]. Nonlinear time history analysis has been carried out in order to obtain the storey shear, pounding force, storey drift, point displacement and acceleration. Mostly familiar El Centro earthquake, 1940 time history function is applied in both longitudinal and transverse direction to investigate response of structures in MDOF system. Influence of separation distance between two structures and effect of different modelling approach by using "frame" and "frame + slab" models are also investigated.

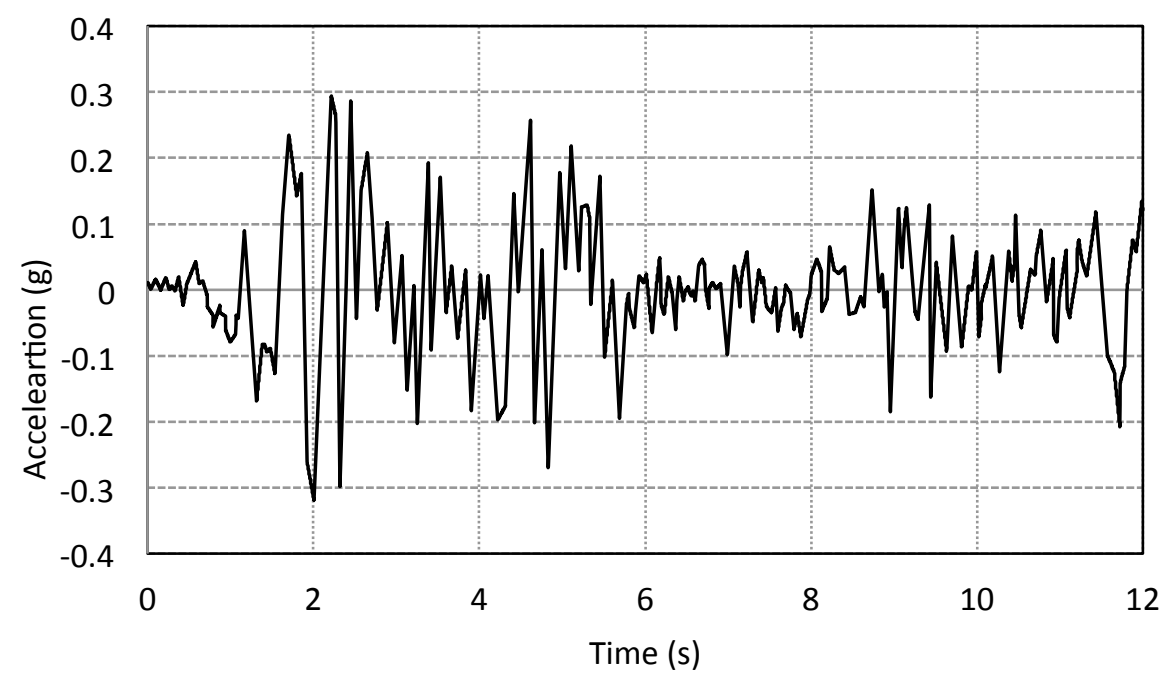

Figure 2 Time history of El Centro earthquake, 1940 


\subsection{Free vibration analysis in Structures}

Eigen frequencies of structures both pounding and no pounding case is shown in Table 1. It can be seen that frequency of structures is higher in pounding state for all the first 20 modes of response. 20the modal frequency for pounding state is $18.56 \mathrm{~Hz}$ while no pounding state is only $12.67 \mathrm{~Hz}$.

Table 1 Natural frequency of buildings for pounding and no pounding state

\begin{tabular}{ccc}
\hline \multirow{2}{*}{ Mode } & \multicolumn{2}{c}{ Frequency $(\mathbf{H z})$} \\
\cline { 2 - 3 } & no pounding & Pounding \\
\hline 1 & 0.789628 & 0.826742 \\
2 & 0.826612 & 0.935424 \\
3 & 0.86974 & 0.99423 \\
4 & 1.41557 & 1.616708 \\
5 & 1.587962 & 2.628625 \\
6 & 1.616527 & 2.75977 \\
7 & 2.657087 & 2.856873 \\
8 & 2.759557 & 5.439868 \\
9 & 2.894792 & 5.440815 \\
10 & 5.298434 & 5.794179 \\
11 & 5.381929 & 5.878342 \\
12 & 5.439838 & 8.888257 \\
13 & 5.682916 & 9.090992 \\
14 & 5.853807 & 9.412119 \\
15 & 5.877893 & 12.67138 \\
16 & 8.939666 & 13.32126 \\
17 & 9.090992 & 13.61897 \\
18 & 9.472837 & 14.01247 \\
19 & 12.21016 & 18.43488 \\
20 & 12.67138 & 18.55529 \\
\hline & &
\end{tabular}

From figure 3, it is observed that mode 1 responses of structures are different in pounding and no pounding state. For pounding state, the taller building and shorter building move forward together due to repeated heavy blows caused by seismic action. For no pounding state, the taller building moves toward left due to lateral loading and forward and the shorter building does not move significantly. 


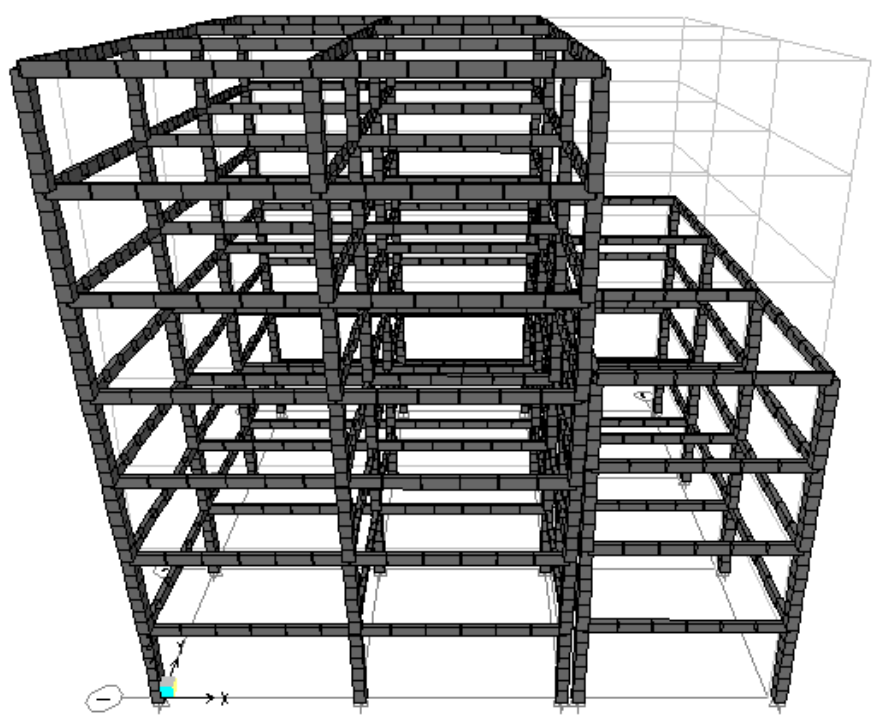

(a) Pounding state

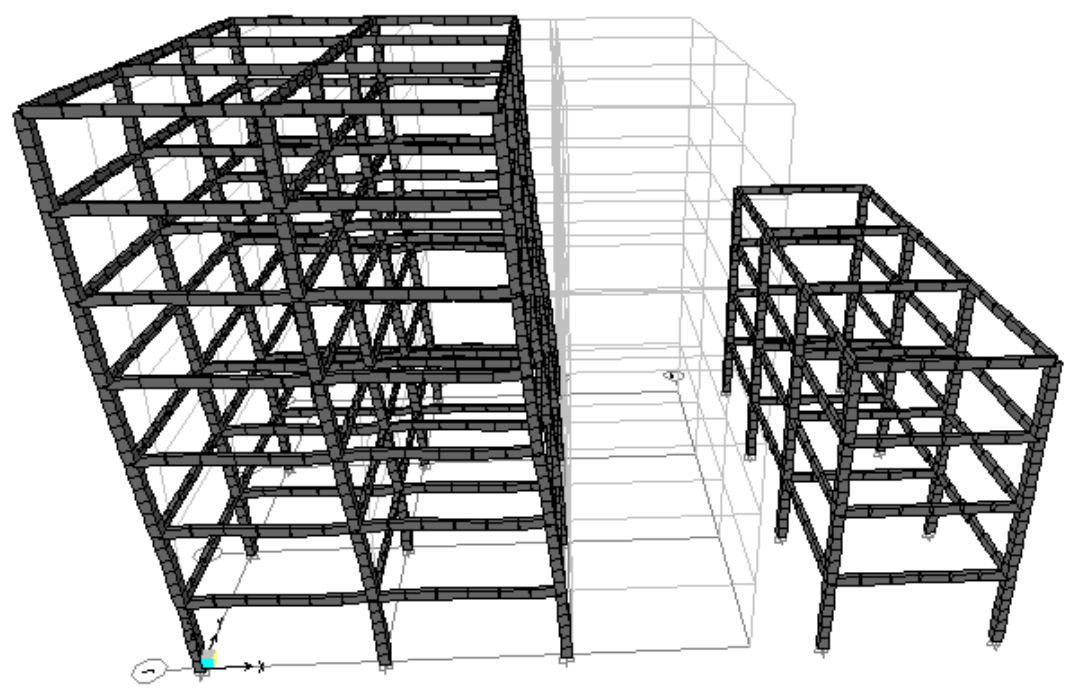

(b) No pounding state

Figure 3 Mode 1 response of buildings for (a) pounding sate and (b) no pounding state

\subsection{Longitudinal Responses of Structures}

Analysis has been carried out in multiple degrees of freedom and response of building in longitudinal and transverse directions are obtained. Figure 4 shows the maximum point displacement at each floor level for the structures in longitudinal direction. 


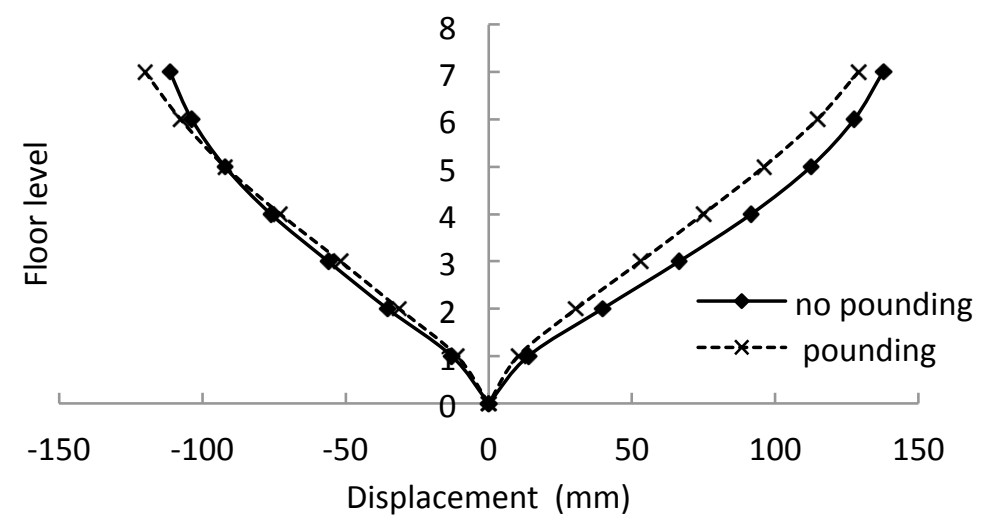

Figure 4 Maximum displacements at different floors (longitudinal direction)

The highest displacement for both no pounding and pounding case occur at roof level of building. Highest roof displacement for no pounding case is $137.62 \mathrm{~mm}$ and for pounding case is 129.07 $\mathrm{mm}$. It has been reduced by $8.55 \mathrm{~mm}$. However, maximum displacement movement toward left shows increase in pounding case. It is $-119.94 \mathrm{~mm}$ while for no pounding case is only $-111.35 \mathrm{~mm}$. It may be due to the flexible nature of taller building that causes it to bounce back after pounding. Maximum negative displacements for floor levels below fifth storey are still lower in pounding state. Generally pounding reduces the lateral displacement throughout the building height. The reduction in displacement is more obvious in direction towards right compared to left, which may be due to overall increase of building stiffness while in contact. These patterns of results have been validated with Maison and Kasai [30]. Similar results had also been obtained in analytical studies for type of structural pounding by Maison and Kasai [30], where analogous reason is also revealed.

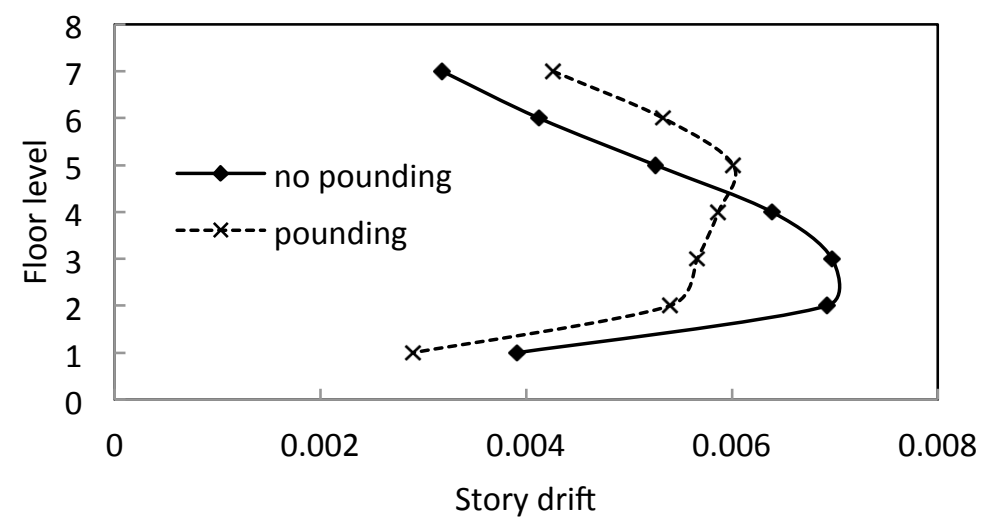

Figure 5 Maximum storey drift at different floors (longitudinal direction)

Figure 5 shows storey drift of each level of building in longitudinal direction. It can be clearly seen that storey drift increase in the levels above the pounding level. Beneath the pounding level, storey drift tends to decrease. For both no pounding and pounding case, smallest storey drift exists in first storey of structures which are 0.003912 and 0.002899 respectively. Largest storey 
drift for pounding case occur just above the level of pounding. The peak storey drift is 0.006012 which is 0.000756 more than no pounding case. The pounding of taller adjacent building creates high storey shear above pounding level. This high storey shear causes the increase in storey drift on each floor level above pounding location.

\subsection{Transverse Responses of Structures}

The pounding involved and independent vibration displacements in transverse direction for each floor level are presented in Table 2. The displacement is gradually increasing as the height of structures increases. It also can be seen that in transverse direction there is no significant difference in displacement for both pounding and no pounding case. It is because transverse responses of structures are only due to the effect of friction force rather than direct impact force of pounding. It is to mention that the friction between the structures was modelled by a linear compensation spring.

Table 2 Maximum displacement at different floor levels in transverse direction

\begin{tabular}{lcc}
\hline & \multicolumn{2}{c}{ Displacement $(\mathbf{m m})$} \\
\hline Storey & no pounding & Pounding \\
\hline ROOF & 130.0404 & 129.9997 \\
& -102.479 & -102.464 \\
STORY6 & 120.3274 & 120.3223 \\
& -95.25 & -95.2297 \\
STORY5 & 106.1364 & 106.1339 \\
& -88.519 & -88.4936 \\
STORY4 & 86.65718 & 86.6521 \\
& -77.7977 & -77.7748 \\
STORY3 & 63.0428 & 63.0428 \\
& -60.7619 & -60.7441 \\
STORY2 & 37.47008 & 37.4777 \\
& -38.1559 & -38.1432 \\
STORY1 & 13.02004 & 13.0175 \\
BASE & -13.6246 & -13.622 \\
& 0 & 0 \\
\hline
\end{tabular}

Table 3 shows the transverse storey drift for each floor level of both the structures. Pounding of structures shows negligible influence in transverse storey drift. It is much less significant as compared to the effect of pounding in longitudinal direction. A study of pounding between main building and stairway tower by Jankowski [31] also shows that main building with considerably large mass and stiffness would response identically for pounding-involved and independent vibration cases in transverse direction. It is because the interaction between the two adjacent structures is mainly at direction of pounding (longitudinal). There is only friction force takes place in transverse direction. 
Table 3 Maximum Storey drift at different floor levels in transverse direction

\begin{tabular}{ccc}
\hline & \multicolumn{2}{c}{ Storey Drift } \\
\hline & no pounding & Pounding \\
\hline ROOF & 0.002938 & 0.002943 \\
STORY6 & 0.004025 & 0.004031 \\
STORY5 & 0.004942 & 0.004954 \\
STORY4 & 0.005964 & 0.005965 \\
STORY3 & 0.007018 & 0.007018 \\
STORY2 & 0.007659 & 0.007659 \\
STORY1 & 0.004533 & 0.004533 \\
\hline
\end{tabular}

\subsection{Pounding Effect on Displacement of Structures}

\subsubsection{Taller Building}

The displacement time history at pounding level of the taller building in longitudinal direction is shown in Figure 6a. Both pounding and no pounding cases show unstable sinusoidal displacement graph. From the graph, it can be seen that amplitude for the pounding case sinusoidal graph are lower compared to no pounding except in the time range of 4 to 5 seconds. The peak displacement at fourth floor level for no pounding case is $91.69 \mathrm{~mm}$ while it is only $74.93 \mathrm{~mm}$ for pounding case. Overall displacement at level four decreases after pounding because shorter building prevents further movement of taller building.

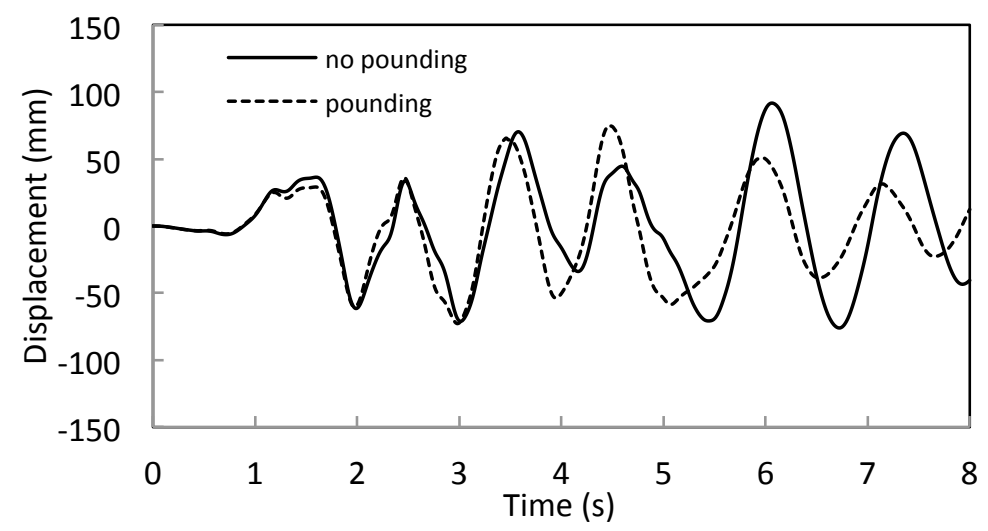

(a) Pounding level

Figure 6 Displacement time history (longitudinal direction) at: (a) pounding level, (b) roof level of taller building 


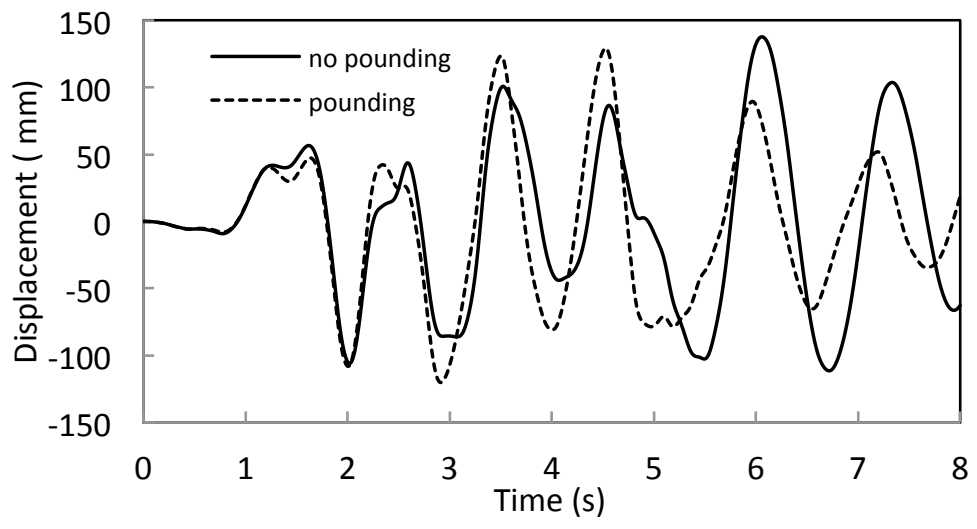

(b) Roof level

Figure 6 (continued) Displacement time history (longitudinal direction) at: (a) pounding level, (b) roof level of taller building

On the other hand, Figure $6 \mathrm{~b}$ shows the displacement time history at roof level of the taller building. Magnitude of displacement at roof level is generally higher than pounding level. It is because of taller object tends to be more flexible than shorter object. From the display, peak displacement at roof level without pounding effect is $137.67 \mathrm{~mm}$ while subjected to pounding effect is $129.03 \mathrm{~mm}$. This is due to the shorter building, which restricted the movement of building below pounding location. It causes high inertia force on level above pounding location. Therefore, displacement of building above pounding location is relatively higher than below pounding location.

\subsubsection{Shorter Building}

Pounding takes place at the roof level of shorter building. Figure 7 shows the longitudinal displacement time history at pounding level of shorter building. From the graph, displacement of no pounding case is not in phase with pounding case. It shows that pounding causes major changes in response of shorter building.

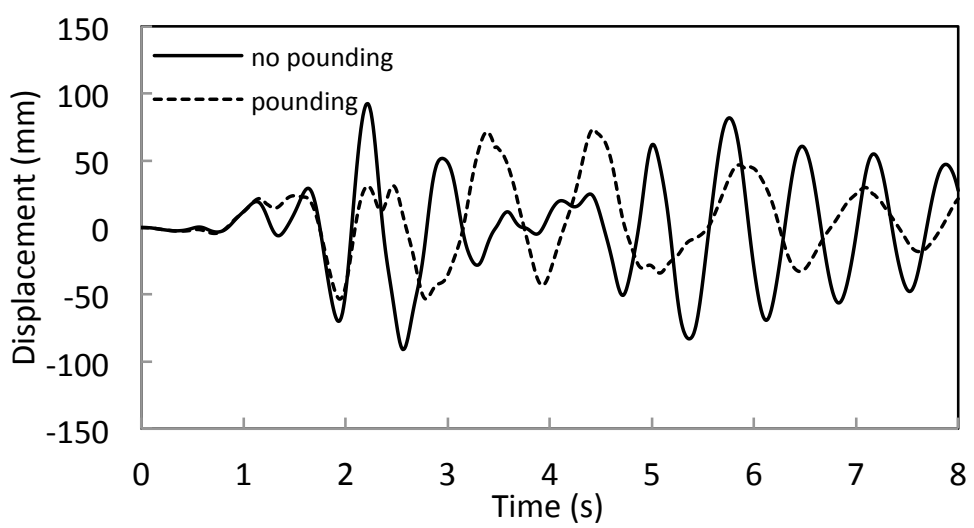

Figure 7 Displacement time history (longitudinal direction) at pounding level of shorter building 
Peak displacement for no pounding state is $92.20 \mathrm{~mm}$ while for pounding state is $72.90 \mathrm{~mm}$. It is equivalent to $20.9 \%$ of decrease in peak displacement. From both Figures 6 and 7 , it can be noticed that pounding reduces displacement of building regardless of building height.

\subsection{Pounding Effect on Acceleration of Structure}

\subsubsection{Taller Building}

During earthquakes, large floor accelerations will be generated due to the vigorous ground motion. These accelerations can increase by multiple times when pounding of structures occurs.

Figure 8a shows the longitudinal acceleration time history at pounding level of taller building. The most obvious change in the graph is that there are few sharp increases in negative accelerations. The crowning negative acceleration is as high as $-43.05 \mathrm{~m} / \mathrm{s}^{2}$ at 3.56 seconds. It is almost 6 times higher compared to no pounding state acceleration which is only $-6.71 \mathrm{~m} / \mathrm{s}^{2}$ at 2.46 seconds.

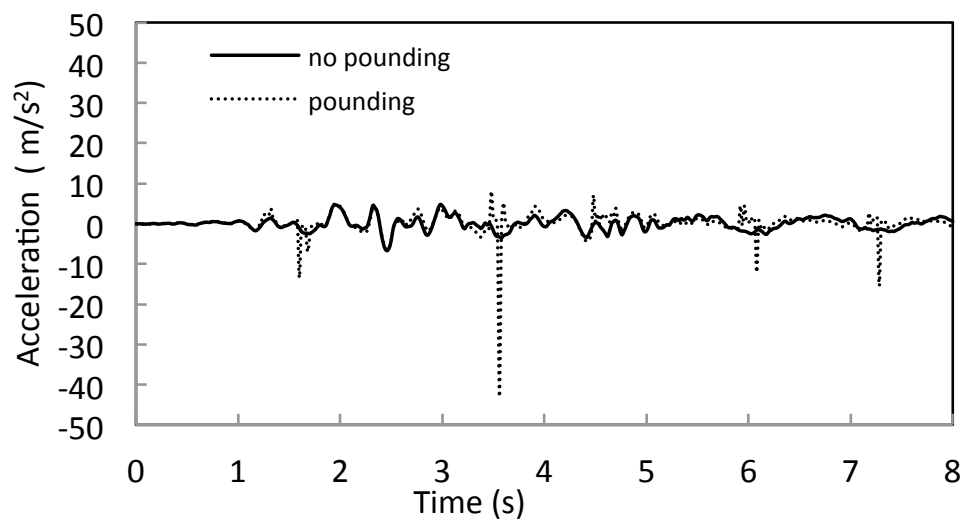

(a) Pounding level

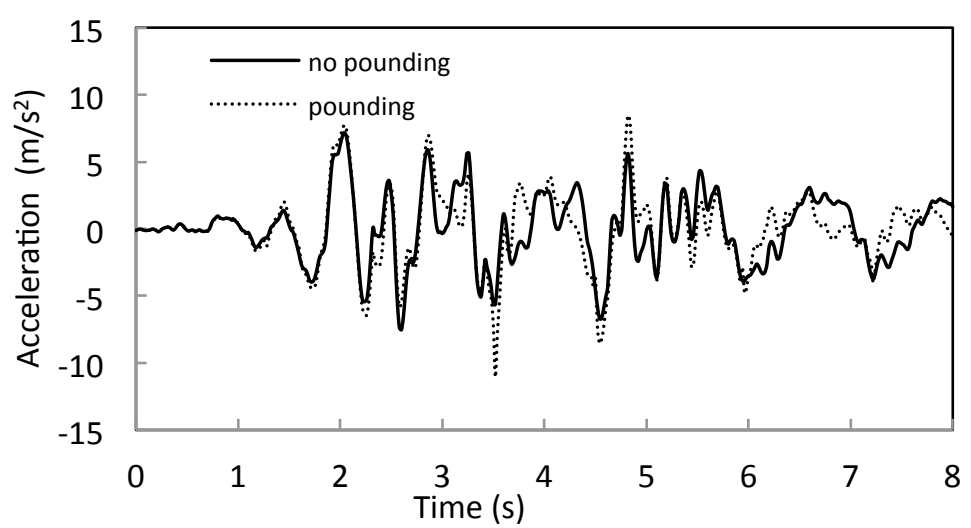

(b) Roof level

Figure 8: Acceleration time history (longitudinal direction) at: (a) pounding level, (b) roof level of taller building

However, accelerations at roof level of taller building do not undergo such abrupt changes as shown in Figure 8b. Uttermost acceleration at roof level in pounding state is $-11.07 \mathrm{~m} / \mathrm{s}^{2}$ while for 
no pounding state it is $7.52 \mathrm{~m} / \mathrm{s}^{2}$. The amplification in acceleration during pounding is only 1.5 times. It indicates that acceleration increases at roof level but not as abrupt as at pounding level.

\subsubsection{Shorter Building}

Figure 9 shows the longitudinal acceleration time history at pounding level of shorter building. Both pounding state diagram in Figures $8 \mathrm{a}$ and 9 shows great similarities in peak accelerations but only in opposite direction. Peak acceleration generated in shorter building during collision is as much as $105.69 \mathrm{~m} / \mathrm{s}^{2}$. It exists 9.7 times more value than the peak acceleration for no pounding case which is only $-10.86 \mathrm{~m} / \mathrm{s}^{2}$. Comparison between the peak acceleration of both building clearly indicates that heavier building will induce high acceleration on lighter building.

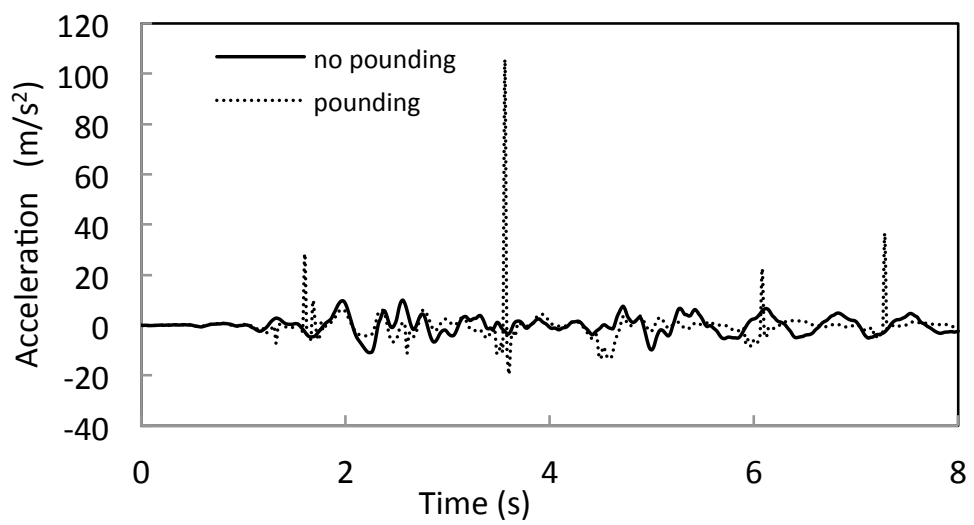

Figure 9 Acceleration time history (longitudinal direction) at pounding level of shorter building

\subsection{Effect of Separation Distance between Structures}

As previous results have shown, the major pounding effect takes place in longitudinal direction of pounding level. Thus, this study observes the changes of pounding force for such condition. Table 4 shows the pounding force generated in link element at pounding level for different separation distances.

Table 4 Pounding force at fourth storey of buildings for different separation distances

\begin{tabular}{cccc}
\hline $\begin{array}{c}\text { Gap distance } \\
(\mathbf{m m})\end{array}$ & Floor level & $\begin{array}{c}\text { Time } \\
(\mathbf{s})\end{array}$ & Pounding force $(\mathrm{kN})$ \\
\hline 25 & $4^{\text {th }}$ & 3.56 & 1374.14 \\
125 & 4 th & 3.62 & 1374.63 \\
250 & 4 th & 4.62 & 878.30 \\
\hline
\end{tabular}

By increasing gap distance from $25 \mathrm{~mm}$ to $125 \mathrm{~mm}$, pounding force does not decrease but slightly increases, as this distance is not enough to reduce the most severe contact between the two structures. For $250 \mathrm{~mm}$ gap, the pounding force has decreased to $878.30 \mathrm{kN}$, i. e.36.8\% reduction, if compared to $25 \mathrm{~mm}$ gap response. This result shows that adequate gap distance be- 
tween the structures will significantly reduce pounding damage. Smaller pounding force is much desirable because it reduces the chances of structures collapse.

Storey shear amplification of each floor level for different gap distance is shown in Figure 10. It shows that taller structures are more likely to suffer greater damage when pounding occurs. The effect of pounding can be clearly seen from the sharp increase of storey shear at level five of building. Another important trend can be seen is that increasing gap distance tends to reduce story shear in consistent manner. For instance, at floor level five, the storey shear amplification for $25 \mathrm{~mm}$ gap is $1.69,125 \mathrm{~mm}$ gap is 1.68 and $250 \mathrm{~mm}$ gap is 1.67 . Though the reduction of storey shear is not large, it implies that providing adequate gap distance is a viable option to reduce pounding damage.

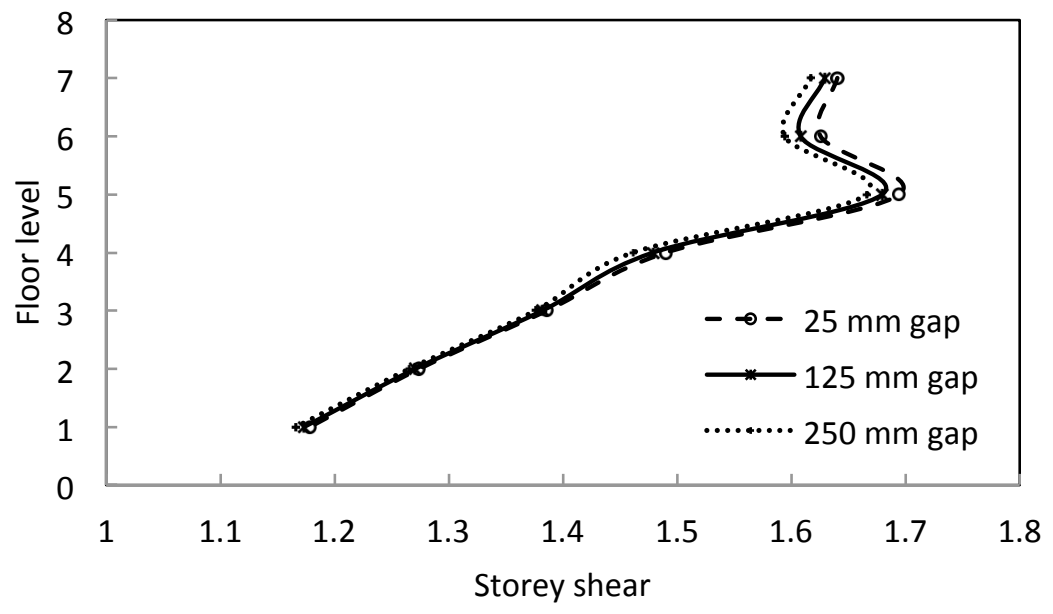

Figure 10 Storey shear amplification at different floor level versus separation distance

\subsection{Evaluation of "Frame + Slab" Model with "frame" model}

Conventionally framed structure modelling had been often used as a basis for comparative research purpose. It is the simplest form of modelling which is computationally efficient. Theoretically, "frame + slab" model will be displaced less as compared to the "frame" model because slab has positive effect on increasing the lateral stiffness of the structure under lateral loads.

Firstly, the display of floor level versus displacement is shown in Figure 11a. The maximum displacement at roof level for "frame + slab" model is $136.78 \mathrm{~mm}$, which is $6 \%$ higher if compared to "frame" model. It can also be seen that both positive and negative displacement of "frame and slab" model is relatively higher. This shows that the theory of reduction in lateral displacement by "frame and slab" modelling is not applicable in case of pounding of structures. This is because slab increases the mass of building generating larger momentum upon pounding. It is known that momentum is directly proportional to object's mass. This large momentum generated during pounding are more significant than the increase of lateral stiffness by slabs. Thus, the building is displaced more in "frame + slab" model.

Figure 11b compares the storey drift for each floor level of building for both the types of modelling concept. For both model, the peak storey drift occurs at level above pounding location. "Frame and slab" model has higher peak storey drift of 0.00714 while frame model is only 0.006012. It is due to higher pounding force generated during collisions. The time history of pounding force at level four can be seen in Figure 11c. The peak pounding force of "frame and slab" model is $3201.38 \mathrm{kN}$. It is 2.3 times higher than frame model which is only $1374.14 \mathrm{kN}$. Such high pounding force causes big difference in displacement between the levels of building. 


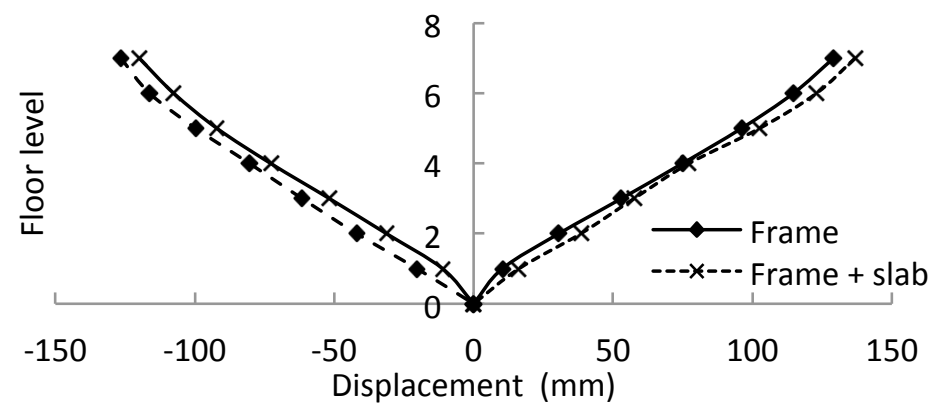

(a) Displacement

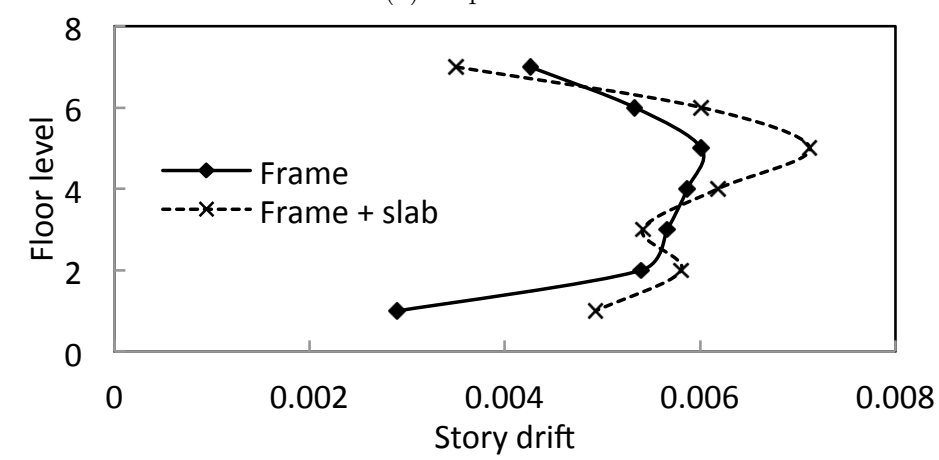

(b) Storey Drift

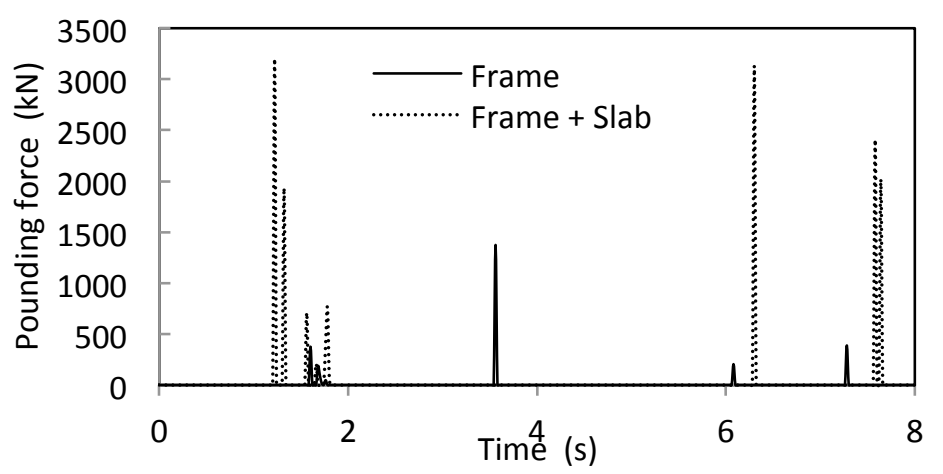

(c) Pounding force

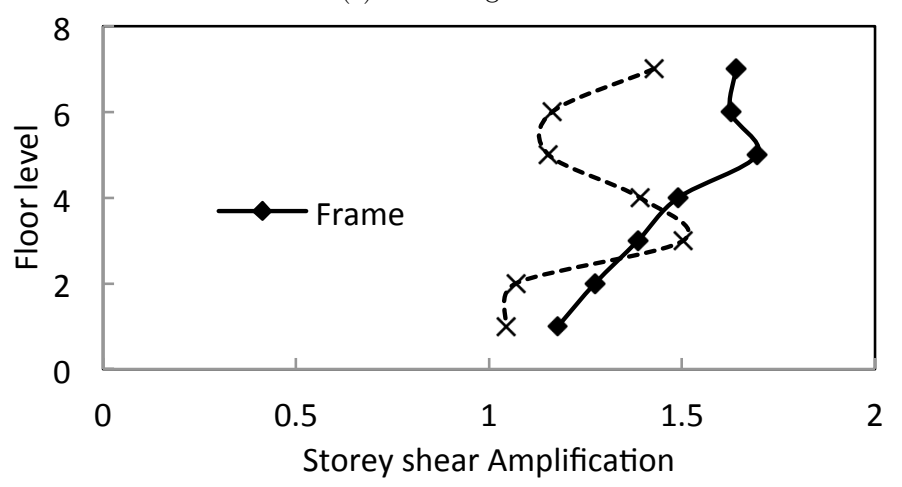

(d) Pounding force

Figure 11 Comparison of building responses (longitudinal direction) for "frame + slab" with "frame" model 
Lastly, illustration of floor level versus shear amplification is shown in Figure 11d. It can be seen that "frame and slab" model does not response similar to frame model. Storey shear of frame model is increasing with the height of building while trend of graph of "frame and slab" model is inconsistent. Generally, shear amplification for "frame and slab" model is lower and only has peak shear amplification of 1.5.It shows that dynamic properties of structures are very important in non-linear dynamic analysis. In this case, it had affected the storey shear of building significantly.

\section{CONCLUSIONS}

The results of present study show that pounding effect may be hazardous for structures. Major findings of this study are as follows:

1. Response of building is greatly affected in the direction of pounding (longitudinal) while response in transverse direction is almost negligible. It is because the direction of pounding (longitudinal) is influenced by impact force but there is only friction force acting on transverse direction.

2. Pounding reduces lateral displacement of structures because movement of structures are blocked by each other. The stiffness of whole system is increased.

3. Acceleration at pounding level of structures greatly increases during collisions. Pounding force is directly proportional to acceleration. This extra pounding force may severely damage the structural members of structures.

4. During pounding lighter building experiences more acceleration and displacement. It is more venerable to damage than building with higher mass.

5. Separation distance between neighbouring structures reduces pounding damage as pounding force is widely decreased for greater separation distance compared to low dimensional gap element.

6. "Frame + slab" model shows higher displacement that only "Frame" model. This is due to inclusion of slab in the model of building, which also increases the mass causing larger momentum during pounding.

7. The conventional modelling of building considering only beams and columns underestimates pounding effects. More realistic modelling such as beams, columns and slabs shall be adopted to accurately understand the pounding phenomenon.

Acknowledgements The authors gratefully acknowledge University of Malaya, Malaysia for supporting this work through research grant RG140-12AET.

\section{References}

[1] E. Rosenblueth, R. Meli, The 1985 earthquake: Causes and effects in Mexico City. Concrete International. 8(1986). 23-24.

[2] You-Wei Zhang, Yan Zhao, Jia-Hao Lin, W.P. Howson and F.W.Williams, "A General Symplectic Method for the Response Analysis of Infinitely Periodic Structures Subjected to Random Excitations", Latin American Journal of Solids and Structures, Vol. 9 (2012) pp. 569 - 579.

[3] D. Lopez-Garcia, T.T. Soong, Assessment of the separation necessary to prevent seismic pounding between linear structural systems. Probabilistic Engineering Mechanics. 24 (2009). 210-223. 
[4] M. Jameel, Islam, A. B. M. S., R.R. Hussain, M. Khaleel (2012). Optimum Structural Modelling for Tall Buildings. The Structural Design of Tall and Special Building, [10.1002/tal.1004].

[5] A. B. M. S. Islam, M. Jameel, M.Z. Jumaat, M.M. Rahman (2013). Optimization in Structural Altitude for Seismic Base Isolation at Medium Risk Earthquake Disaster Region. Disaster Advances, 6(1), 23-34.

[6] J. Penzien, Evaluation of building separation distance required to prevent pounding during strong earthquakes. Journal of Earthquake Engineering and Structure Dynamics. 26 (1997) 849 - 858.

[7] M. Dogan, A. Gunaydin, Pounding of adjacent RC buildings during seismic loads. Journal of Engineering and Architecture Faculty of Eskisehir Osmangazi University. 22(2009) 129-145.

[8] K. Kasai, V. Jeng, P.C. Patel, J.A. Munshi, B.F. Maison, Seismic pounding effects - Survey and analysis. Earthquake Engineering, 1992, Tenth World Conference.

[9] A.B.M. S. Islam, S.I. Ahmad, M. Jameel, M.Z. Jumaat, Seismic Base Isolation for Buildings in Regions of Low to Moderate Seismicity: A Practical Alternative Design. Practice Periodical on Structural Design and Construction, ASCE, 17(2012):13-20.

[10] A. B. M. S. Islam, M. Jameel, M.Z. Jumaat (2012). Review of offshore energy in Malaysia and floating Spar platform for sustainable exploration. 16(8), 6268 - 6284. Renewable \& Sustainable Energy Reviews.

[11] A.B.M. Islam, M. Jameel, M.Z. Jumaat, Study on optimal isolation system and dynamic structural responses in multi-story buildings. International Journal of Physical Science 6(2011): 2219 - 2228.

[12] K. Kasai, B.F. Maison, Building pounding damage during the 1989 Loma Prieta earthquake. Engineering Structures. 19(1997) 957-977.

[13] R. Jankowski, Non-linear viscoelastic modelling of earthquake-induced structural pounding. Earthquake Engineering and Structural Dynamics. 34(2005) 595-611

[14] R. Jankowski, Pounding force response spectrum under earthquake excitation, Engineering Structures. 28(2006). 1149-1161.

[15] V. Jeng, V, W.L. Tzeng, (2000). Assessment of seismic pounding hazard for Taipei City. Engineering Structures. 22(2000) 459-471.

[16] R. Jankowski, Earthquake-induced pounding between equal height buildings with substantially different dynamic properties. Engineering Structures. 30 (2008). 2818-2829.

[17] A.B.M. Islam, M. Jameel , M.Z. Jumaat, Seismic isolation in buildings to be a practical reality: behavior of structure and installation technique. Journal of Engineering and Technology Research 3(2011): 97-117.

[18] E.L. Harkness, M.A. Hassanain, Seismic damage in NSW, Australia: construction insurance, social, and economic consequences. Journal of Performance of Constructed Facilities. 16(2002). 75-84.

[19] A. B. M. S. Islam, M. Jameel, M.Z. Jumaat (2012). Review of offshore energy in Malaysia and floating Spar platform for sustainable exploration. 16(8), 6268 - 6284. Renewable \& Sustainable Energy Reviews.

[20] A.B.M. Islam, M. Jameel, S.I. Ahmad, M.Z. Jumaat, Study on corollary of seismic base isolation system on buildings with soft story. International Journal of Physical Science 6(2011): 2654-2661.

[21] R.R. Hussain, T. Ishida. Computer-aided oxygen transport model of mass and energy simulation for corrosion of reinforced steel, Automation in Construction, Volume 20, Issue 5, August 2011, Pages 559-570.

[22] A. B. M. S. Islam, M. Jameel, M.Z. Jumaat (2012). Oil and gas energy potential at Malaysian sea beds and Spar platform for deep water installation. International Journal of Green Energy, 9(2),111-120.

[23] M. Jameel, A. B. M. S. Islam, M. Khaleel, L.T. How (2013). Nonlinear analysis of marine riser for energy exploration in shallow and deep water regions. Energy Education Science and Technology Part A-Energy Science and Research, 31(1), 187-206.

[24] M. Jameel, S. Ahmad, A. B. M. S. Islam, M.Z. Jumaat (2013). Nonlinear dynamic analysis of coupled spar platform. Journal of Civil Engineering and Management. DOI:10.3846/13923730.2013.768546.

[25] A.B.M. Islam, R.R. Hussain, M. Jameel, M.Z. Jumaat. Automated Non-linear Time Domain Analysis of Base Isolated Multi-storey Building under Site Specific Bi-directional Seismic Loading, Automation in Construction. 22(2012): $554-566$.

[26] Z. Ren, C.J. Anumba, G. Augenbroe, T.M. Hassan, A functional architecture for an e-Engineering hub, Automation in Construction 17(2008) 930-939.

[27] IBC, 2009. International Building Code.

Latin American Journal of Solids and Structures 10(2013) $921-939$ 
[28] A. Habibullah, 2007. ETABS Three Dimensional Analysis of Building Systems. Computers and Structures, Inc., Berkeley, California.

[29] E. Wilson, 2002, Three-dimensional static and dynamic analysis of structures, 3rd ed. Berkeley: Computers \& Structures Inc.

[30] B.F. Maison, K. Kasai, (1990). Analysis for Type of Structural Pounding, Journal of Structural Engineering. 116(1990). 957-977.

[31] R. Jankowski, Non-linear FEM analysis of earthquake-induced pounding between the main building and the stairway tower of the Olive View Hospital. Engineering Structures. 31(2009). 1851-1864. 